\title{
Oral Lichenoid Contact Reaction to a Complete Denture
}

Dhruv Dubey ${ }^{1}$

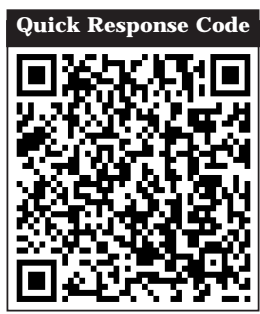

doi: $10.5866 / 2015.7 .10293$

1Post Graduate Student

Department of Periodontology

Army Dental Centre Research \& Referral,

Delhi Cantt

India

\section{Article Info:}

Received: October 12, 2015

Review Completed: November 11, 2015

Accepted: December 10, 2015

Available Online: March, 2016 (www.nacd.in)

(c) NAD, 2015 - All rights reserved

\section{Email for correspondence:}

dddrdent@rediffmail.com

\begin{abstract}
:
Oral lichenoid lesions (OLLs) or oral lichenoid reactions (OLRs) share common clinical and histological features to oral lichen planus (OLP). OLRs have sometimes been considered as part of OLP, and havealso been described as contact al lergies, or contact lesions. Local allergic contact hypersensitivity, termed as oral lichenoid contact reaction (OLCR) though uncommon, have been reported as a local tissue responseto a variety of dental materials such as restorative materials, impression materials and dentures. Oral lichenoid contact reactions share common dinical and histological features to oral lichen planus (OLP), which is an auto immune disorder exaggerated in theoral cavity. Lesions of OLCR in relation to dental acrylic prosthesis are located in apposition or in near proximity to the denture base, and lesions are limited to such sites of contact. This article presents a rare case of oral lichenoid contact reaction to acrylic denture base. The lesion was initially thought to be a soft tissue fibroma due to chronic denture irritation. The definitive diagnosis was completely based on the histological analysis of the tissue sample, which confirmed the typical lichenoid characteristics of the lesion.
\end{abstract}

Key words: Oral lichenoid lesion, Oral lichenoid reaction, Oral lichenoid contact reaction.

\section{INTRODUCTION}

Oral lichenoid reaction (OLR) or oral lichenoid lesions (OLL) is a term that represent a common end point in response to extrinsic agents (materials, allergens), altered self-antigens, or super antigens. OLL is thus used to describe eruptions of the oral cavity having an identifiable etiology, which are clinically and histologically similar to oral lichen planus (OLP). ${ }^{1}$

In the literature, different terms are used to refer to these lesions. OLRs have sometimes been considered as part of OLP, and have also been described as contact allergies, oral lichenoid lesions, or contact lesions. ${ }^{2-7}$ The term OLR was proposed by Finne in 1982 to designate clinically indistinguishable lesions of OLP. ${ }^{2}$ Oral lichenoid reactions may also result from systemic drug exposure, termed as oral lichenoid drug reaction (OLDR), or local allergic contact hypersensitivity, termed as oral lichenoid contact reaction (OLCR). Oral lichenoid lesions share common clinical and histological features to oral lichen planus (OLP), which is an auto immune disorder exaggerated in the oral cavity. 
Since this concept was proposed, these lesions have been described as a response to a wide variety of triggering factors and said to involve several clinical types. OLR presenting as contact-stomatitis, relates to immune mediated hypersensitivity. These have been discovered to be in direct topographic relation with dental restorative materials, most commonly with amalgam. Though OLRs related to non-metallic dental materials are notably less frequent than those to metallic materials, cases presenting the reaction to denture base materials, dental cements, endodontic irrigants have been documented.

Here is a report that presents such an exceptional case of oral soft tissue contact reaction to acrylic base denture material in the form of a soft tissue enlargement occupying the vestibule.

\section{CASE REPORT}

A 56 year old female patient, wife of a retired personnel, reported to the Department of Periodontology, Army Dental Centre R \& R Delhi Cantt, with the chief complaint of swelling in the upper front gums since the last 3 months and difficulty in wearing dentures due to the same reason. The history of present illness revealed that the patient was asymptomatic 3 months back, and the present complaint started with mild pain in the upper front gums, following which the patient noticed redness in the region. A painless growth appeared in the region which grew to the present size over the past three months.

U pon eliciting the medical history, the patient reported no underlying disease or conditions for which she is seeking, or has undergone any medical consultation. She was not on any medications, no admissions to hospital or a day care facility in the last 6 months, and reported to be otherwise systemically healthy. The patient gave a history of uneventful child bearing and delivery twice, and attainment of menopause at the age of 45 years.

Past dental history revealed multiple tooth extractions over past 20 years. The prime reason for the extractions was dental caries and tooth mobility. The patient had been using dentures for the past 2 years.
Family history was non contributory. On general physical examination she was moderately built, adequately nourished and with erect posture. There were no clinical signs of anemia, cyanosis or icterus. Extra oral examination revealed a bilaterally symmetrical face with no sinus, swelling or scar. A convex lateral facial profile, $5 \mathrm{~cm}$ of mouth opening and competent lips at rest were noted. TMJ was normal on palpation and visual examination.

Dental examination revealed completely edentulous maxillary arch, and partially edentulous mandibular arch with presence of the anterior teeth and first premolars bilaterally. The patient wore upper a complete denture and a partial lower denture since last 2 years. On examining the dentures it was noticed that the maxillary dentures were slightly overextended at the labial vestibular area.

The buccal and labial mucosa was normal in color, contour and consistency. A mucosal overgrowth was observed in the upper anterior vestibular area on either side of the labial frenum (Figure 1). The color of the lesion was pink and in confluence with the adjoining mucosa, the size measured at approximately $2 \mathrm{~cm}$ in length, $1 \mathrm{~cm}$ in width, and $0.5 \mathrm{~cm}$ in breadth. The lesion was pedunculated, non-tender, non-pulsatile, and firm in consistency on pal pation. The mucosal attachment was free from the underlying bone and freely movable with the mucosal retraction. Radiographic analysis was carried out using Ortho Pentamo Gram and IOPA radiograph of the involved site. No osseous lesions or pathology was noted (Figure 2).

Based on the patient history, clinical and radio graphical examination a provisional diagnosis of a soft tissue fibroma due to chronic denture irritation was arrived at. A unilateral excisional biopsy of the lesion of the right side, followed by histological examination was planned to arrive at a correct diagnosis. I nitially only one lesion was undertaken for biopsy to diagnose the lesion and to avoid additional post operative morbidity and discomfort to the patient.

A complete hematological analysis including complete blood count, INR, APTT, fasting/ post prandial blood glucose estimation was carried out, 


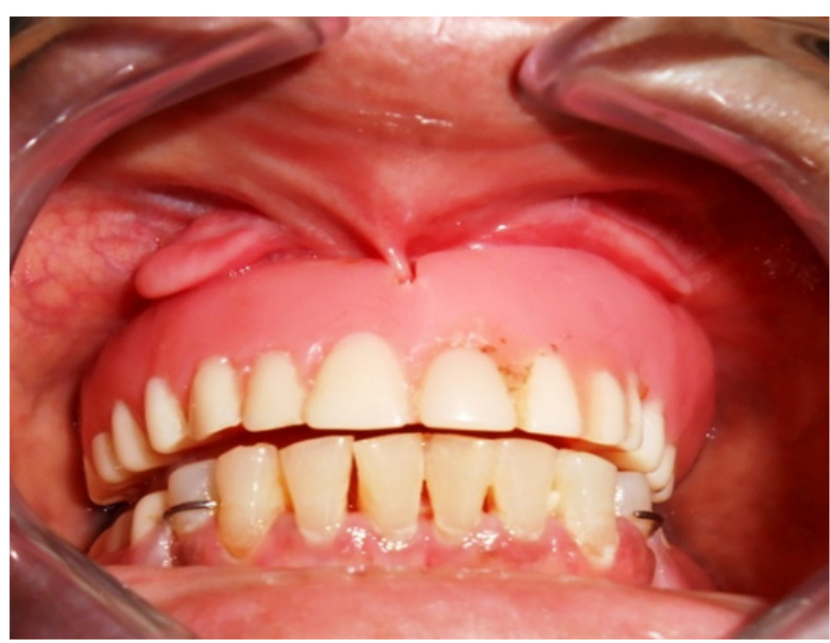

Figure 1: Mucosal overgrowth in the upper anterior vestibular area on either side of the labial frenum.

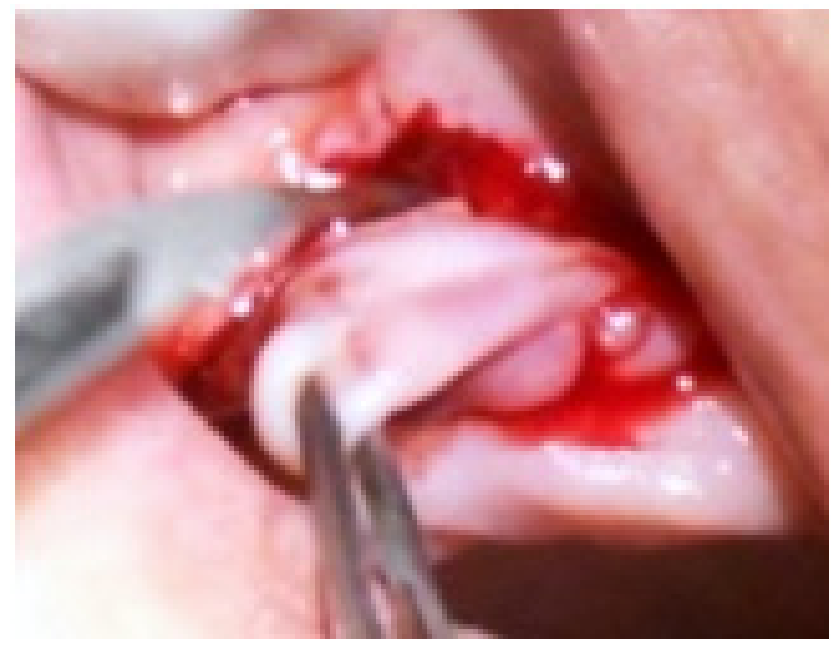

Figure 3: A cicumferential full thickness incision and total lesion removal.

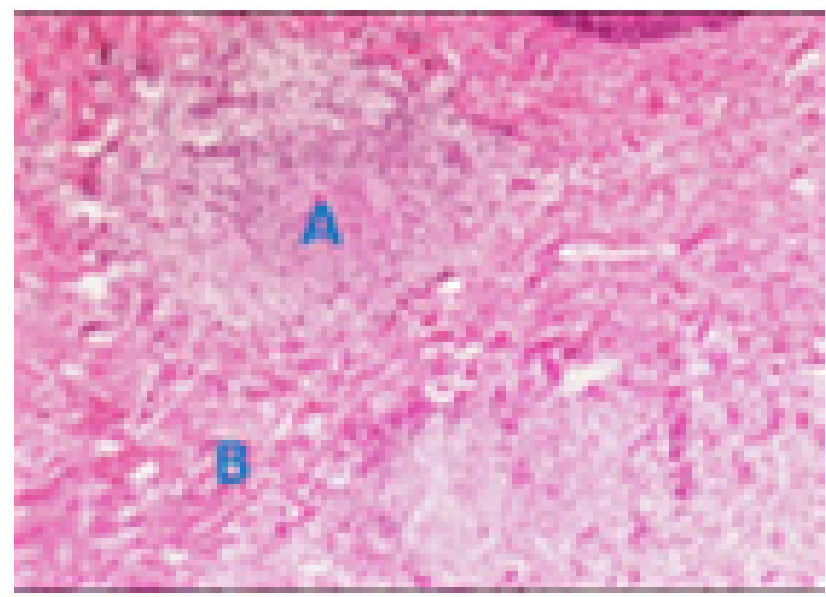

Figure 5: Two distinct patterns of plasma cell infiltration in the dermo-epidermoid junction - One dense and focal (A), and the other scant to moderate diffuse (B).

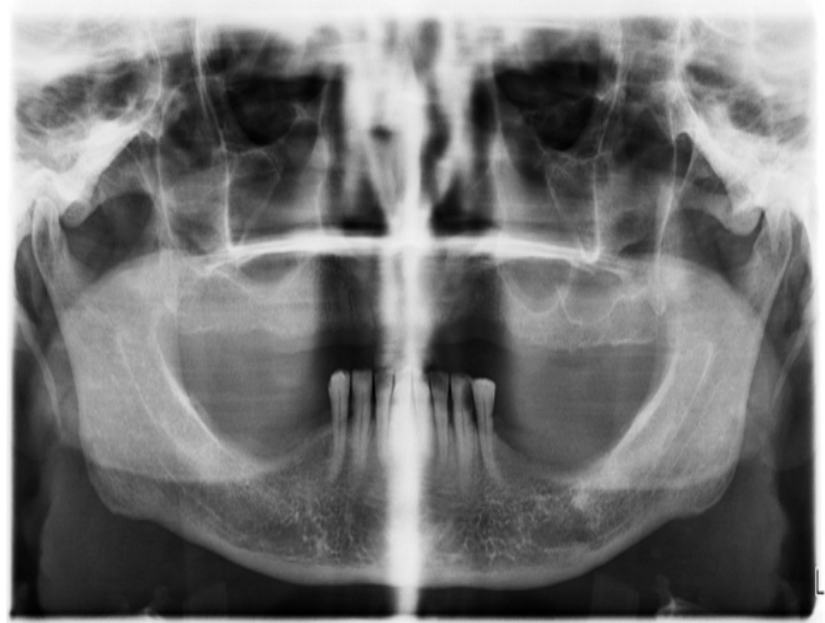

Figure 2: Ortho Pantamo Gram (OPG) showing no osseous lesions or pathology.

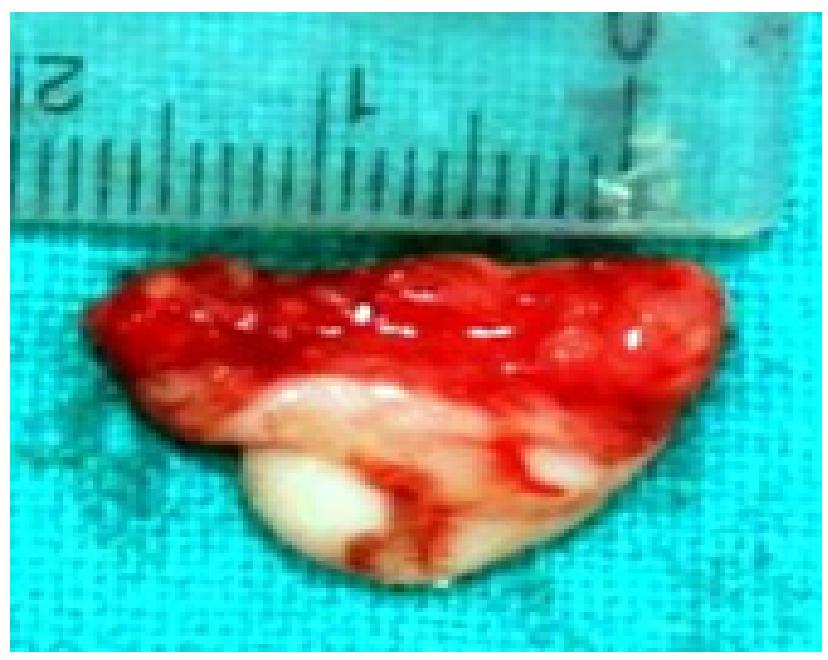

Figure 4: Excised tissue measuring about $1.5 \times 1 \mathrm{~cm}$

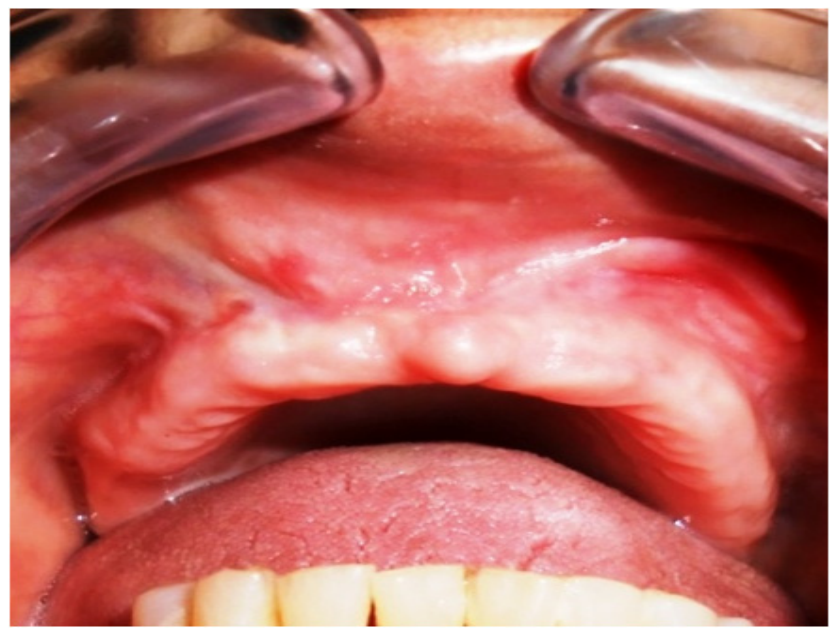

Figure 6: Three month post-operative evaluation revealed satisfactory healing without keloid formation

Indian J Dent Adv 2015; 7(4): 293-297 
with normal results.

The surgical site was prepared with extra oral disinfection by $5 \%$ povidine iodine scrub, and intraoral $0.2 \%$ chlorhexidinerinse. Local anesthesia in the form of ring infiltration with $2 \%$ lignocaine $\mathrm{HCL}$ with 1:80000 adrenaline was administered by a 30 gauge needle, circumferentially around the lesion in the healthy mucosa.

A 15 c blade was used to give a full thickness incision surrounding the lesion on all sides. The incision included $2 \mathrm{~mm}$ of healthy, uninvolved mucosa on the lesion periphery. The full thickness incision and the involvement of the healthy tissue in the incision design, assured the removal of the lesion in total (Figure 3), failure of which could lead to relapse. The surgical site was sutured with interrupted 3-0 silk, and healing by primary intention was aimed. The patient was advised to discontinue wearing dentures and not to brush on the operated site till the removal of the sutures. Analgesics in the form of I buprofen 400mg twice daily for 2 days and mouth rinse with $0.2 \%$ chlorhexidine gluconate twice daily for 1 week were prescribed. The patient was recalled after 24 hours to check for any uneventful morbidity, which was ruled out and suture removal was planned 10 days post operatively.

The excised tissue measuring $1.5 \mathrm{~cm}$ by $1 \mathrm{~cm}$ (Figure 4) was immediately fixed and transported in $10 \%$ formalin solution, to the Department of Pathology, Army Hospital R\&R Delhi Cantt for histological examination.

The histological analysis of $\mathrm{H} \& \mathrm{E}$ stained section of the lesion revealed squamous cell epithelial lining showing acanthosis and focal elongation of rete pegs in 'saw tooth' shaped pattern. Two distinct patterns of plasma cell infiltration (Figure 5) in the dermo-epidermoid junction were seen - One dense and focal and the other scant to moderate diffuse. Dermal edema with no evidence of malignancy were noted. The lesion was identified as a Lichenoid reaction. Based on patient medical and dental history a diagnosis of oral lichenoid contact reaction (OLCR) to dental material, i.e. acrylic based denture material was arrived at.
The patient was informed and advised to discontinue wearing dentures till the complete healing of thesurgical site. Suture removal was done 10 days post operatively. Three month postoperative evaluation revealed satisfactory healing without keloid formation (Figure 6).

\section{DISCUSSION}

The etiology of LP is still under discussion, with a tendency to self-immunity, while the etiology of OLRs is related to the contact with specific agents, such as metallic restorative materials, resins, and drugs, allowing the establishment of a cause-effect relationship.

In the present case, the tissue alteration is thought to be caused by the antigen fixation in the keratinocytes, which are recognized and destructed by cells of the immune system. ${ }^{8,9}$ Denture base dental materials play a fundamental role in the appearance of OLCR in the oral mucosa. The reaction to resin materials was reported by Blongren et al. ${ }^{10} \mathrm{Ali}$ et al. studied hypersensitivity to acrylic denture base material, and noted resolution of the lesions of mouth after removal of the prosthesis. ${ }^{11}$

Lesions of OLCR in relation to dental acrylic prosthesis are located in apposition or in near proximity to the denture base, and lesions are limited to such sites of contact. Typical sites include the lateral borders of the tongue and buccal/ labial mucosa and the buccal/ labial vestibular areas. In the case discussed, the denture flange at the maxillary labial vestibule was evaluated to be a bit over extended. This might have caused repeated impingement of the approximating soft tissue, causing a frank lesion. The lesion with increased vascularity on contact with the denture material might have caused the exuberant lichenoid response as presented.

The lesion was initially thought to be a soft tissue fibroma due to chronic denture irritation. The definitive diagnosis was completely based on the histological analysis of the tissue sample and confirmed the typical lichenoid characteristics of the lesion. Nonappearance of any lesions on other sites of contact with the denture is still not understood. The non-recurrence of the lesion after the excision 
of the same and advice of discontinuing the wearing of denture is in accordance to the study by Ali et al. ${ }^{11}$

\section{Conclusion}

Lichenoid lesions of the oral mucosa present a diagnostic challenge. It may be difficult to distinguish OLP, OLDR, and OLCR on the basis of clinical and/or histological findings. It is essential to obtain a thorough history and perform a complete mucocutaneous examination in addition to specific diagnostic testing (i.e., DIF, IIF, cutaneous patch testing). Generally, OLDR and OLCR resolve once the causative agent has been discontinued.

\section{References}

1. Eisen D, Carrozzo M, Bagan Sebastian J V, Thongprasom $K$. Number $V$ Oral lichen planus: clinical features and management. Oral Dis 2005; 11:338-349.

2. Finne K, Goransson K, Winckler L. Oral lichen planus and contact allergy to mercury. Int J Oral Surg 1982; 11:236239.

3. Ismail SB, Kumar SK, Zain RB. Oral lichen planus and lichenoid reactions: etiopathogenesis, diagnosis, management and malignant transformation. J Oral Sci 2007; 49:89-106.
4. Bolewska J, Hansen $\mathrm{HJ}$, Holmstrup P, Pindborg J J, Stangerup M. Oral mucosal lesions related to silver amalgam restorations. Oral Surg Oral Med Oral Pathol 1990; 70:55-88.

5. Laine , Kalimo K, Happonen RP. Contact allergy to dental restorative materials in patients with oral lichenoid lesions. Contact Dermatitis 1997; 36:141-146.

6. Pang BK, Freeman S. Oral lichenoid lesions caused by allergy to mercury in amalgam fillings. Contact Dermatitis 1995; 33:423-427.

7. Skoglund A. Value of epicutaneous patch testing in patients with oral, mucosal lesions of lichenoid character. Scand J Dent Res 1994; 102:216-222.

8. Thornhill MH, Pemberton MN, Simmons RK, Theaker ED. Amalgam-contact hypersensitivity lesions and oral lichen planus. Oral Surg Oral Med Oral Pathol Oral Radiol Endod 2003; 95:291-299.

9. Weedon D. The lichenoid tissue reaction. Int J Dermatol 1982; 21:203-206.

10. Blongren J , Axéll T, Sandahl O, J ontell M. Adversereactions in the oral mucosa associated with anterior composite restorations. J Oral Pathol Med 1996; 25:311-313.

11. Ali A, Bates J F, Reynolds AJ, Walker DM. The burning mouth sensation related to the wearing of acrylic dentures: An investigation. Br Dent J 1986; 161:444-447.

\section{Gain quick access to our journal online View our journal at www.nacd.in}

